\title{
Comunidades Quilombolas do MT: descrição do português falado 1
}

\author{
Quilombola Communities of Mato Grosso: Description of Portuguese Spoken
}

Antonio Carlos Santana de Souza ${ }^{2}$

Universidade do Estado de Mato Grosso

\begin{abstract}
- RESUMO: Este artigo trata da influência do contato linguístico que envolve quilombolas em diferentes áreas sócio-geográficas do Mato Grosso (MT). Para investigar a variedade do português falado nessas comunidades, nos baseamos na perspectiva teórica da dialetologia pluridimensional, conforme Thun (1998), Radtke e Thun (1996), a qual inclui nas pesquisas linguísticas diferentes dimensões espaciais e sociais em comunidades de fala distintas. Os comportamentos linguísticos dos membros das comunidades afro-brasileiras pesquisadas, no MT, convergem de modo geral para uma orientação centrífuga, que se contrapõe à noção de isolamento que tradicionalmente se associa a esse tipo de contexto, visto que a perda de marcas de africanidade e adoção de marcas da variedade do português brasileiro e regional do entorno é uma constante.
\end{abstract}

- PALAVRAS-CHAVE: Contato linguístico; Quilombolas; Dialetologia pluridimensional; Africanidade; Português brasileiro.

- ABSTRACT: This article deals with the influence of language contact involving quilombolas in different areas. geographical area of Mato Grosso (MT). To investigate the variety of Portuguese spoken in these communities, based on the theoretical perspective of multidimensional dialectology, according to Thun (1998), Radtke and Thun (1996), which includes in linguistic research different spatial and social dimensions in speech communities different. The linguistic behaviors of the members of the Afro-Brazilian communities surveyed, in MT, generally converge on a centrifugal orientation, which contrasts with the notion of isolation that traditionally associated with this kind of context, since the loss of Africanness. Brands of the variety of Brazilian and regional Portuguese in the surrounding area is a constant.

- KEYWORDS: Linguistic Contact; Quilombolas; Multidimensional dialectology; Africanity; Portuguese-Brazilian.

\section{Introdução}

As pesquisas e enfoques na área de Sociolinguística e Dialetologia tem como foco central o estudo da relação entre o uso da língua falada e o contexto social. A correlação entre esses dois eixos - linguístico e extralinguístico - em situações de contatos linguísticos e de plurilinguismo envolvendo línguas minoritárias em contato com o português, no entanto, só nos últimos anos, a partir das políticas de fomento da diversidade linguística vem ganhando um impulso mais significativo (cf. MELLO; ALTENHOFEN; RASO, 2011; ALTENHOFEN, 2013).

Neste artigo nosso objeto de estudo aparece nessa perspectiva abordado como "língua afro-brasileira", sendo o tipo de contato historicamente um contato africano-

\footnotetext{
${ }^{1}$ O presente trabalho foi realizado com apoio da Coordenação de Aperfeiçoamento de Pessoal de Nível Superior Brasil (CAPES) - Código de Financiamento 001

${ }^{2}$ Doutor em Linguística. Bolsista PNPD/CAPES no PPGEL-UFMT. E-mail: acssuems@gmail.com
} 
português, porém sincronicamente uma modalidade de contato intervarietal, de variedades do português de base histórica distinta.

Segundo essa perspectiva, o português afro-brasileiro guarda uma especificidade no universo mais amplo do português popular rural brasileiro (ou, mais precisamente, norma popular rural do português brasileiro), não apenas pelas características sociohistóricas próprias às comunidades em que ele é falado, mas, sobretudo, pelas características linguísticas que o distinguiriam das demais variedades do português popular do Brasil (ou melhor, da norma popular brasileira) (LUCCHESI; BAXTER; RIBEIRO, 2009, p. 32).

Da complexidade desses fatores, ou dimensões de análise, derivam os seguintes objetivos específicos em forma de perguntas de pesquisa:

a. Como se constituiu e constitui a variedade local das comunidades afrobrasileiras, considerando seu "insulamento" em uma área específica, sua identidade (étnica) e os diferentes fatores sócio-históricos tanto internos (da comunidade) quanto externos (de seu entorno)?

b) Cada um desses pontos mantém/substitui variantes de origem africana ou mais arcaicas? Isto é, configura-se aí uma variedade mais conservadora ou mais contemporânea?

c) Se distancia/aproxima do standard/substandard do português do Brasil? Quer dizer, mostram uma variedade mais normatizada ou mais popular? Caracteriza-se como:

$[+$ divergente $]$
$[+$ conservador/ arcaico $]$
$[+$ africano $]$
$[+$ popular $]$

O procedimento central de leitura/análise dos mapas de variáveis lexicais consiste em verificar, antes de tudo, onde predominam variantes [+ afro] e onde se impôs uma variante [- afro] do português do entorno. Essa ocorrência, de acordo com a "técnica de entrevista em três tempos" que inclui os passos perguntar (obter resposta espontânea) + insistir (ampliar o leque de variantes conhecidas espontaneamente) + sugerir (obter a aprovação de conhecimento [passivo] ou desconhecimento de uma variante ainda não mencionada espontaneamente) - pôde-se registrar diferentes graus de manutenção ou perda parcial e total de variantes associadas a uma marca linguística [+ afro].

Em suma, o interesse deste estudo centra-se no comportamento linguístico dos falantes no que tange à conservação ou perda de marcas de africanidade (leia-se também incorporação de marcas [- afro] do português contemporâneo ou reincorporação/ reintegração de marcas [+ afro] via português brasileiro). Ao lado desse interesse nas variáveis sociais, temos que inquirir, enfim, sobre diferenças em relação às variáveis linguísticas nos níveis fonético-fonológico (QFF) e léxico-semântico (QSL).

Temos, assim, dois planos de análise: o plano de análise das variáveis sociais com foco nas dimensões diageracional e diatópica, além da dimensão diassexual, na comparação entre contextos topostáticos distintos; e o plano das variáveis linguísticas, visando entender onde a língua como sistema oferece mais resistência ou abertura, respectivamente à manutenção ou perda de marcas [+ afro] / [- afro] .

\section{Análise dos dados cartografados}

A partir do questionário utilizado nas entrevistas nos sete pontos de pesquisa descritos foram elaborados mapas das variáveis que numa primeira filtragem se mostraram mais relevantes. Do QFF (questionário fonético-fonológico) resultaram 22 
mapas linguísticos. Do QSL (questionário semântico-lexical), resultaram em contrapartida 54 mapas linguísticos. O número maior de mapas produzidos com dados do léxico não reflete necessariamente o número maior de variáveis léxico-semânticas, e sim decorre da técnica em três tempos que possibilita várias leituras e recortes a partir de uma única pergunta. Neste sentido, os mapas do QSL foram de três tipos básicos:

1) Mapas das respostas espontâneas;

2) Mapas de ocorrência de uma variante/forma específica (inclui ocorrência como resposta espontânea e como sugerência);

3) Mapas da sugerência de uma variante comum conhecida/não conhecida pelo falante.

\subsection{Mapeamento de variáveis do QFF}

Conforme se assinalou acima, foram selecionadas do QFF 22 perguntas que incluem as seguintes variáveis:

a) vibrante em posição intervocálica;

b) vibrante em início de sílaba;

c) vibrante em coda silábica;

d) lateral dental em coda silábica;

e) lateral dental em posição tônica;

f) lateral palatal em posição pós tônica;

g) palatalização da oclusiva dental/inclinada em posição tônica;

h)palatalização da oclusiva dental/inclinada em posição pós tônica;

i) realização da vogal diante de sibilante (ditongação);

j) ditongo nasal [ )w)];

1) realização de ['mũitr];

m) palatalização da sibilante $[\mathrm{s}] /$ inclinada.

\subsection{Mapeamento de variáveis do QSL}

De um total de 20 perguntas selecionadas do Questionário Semântico Lexical (QSL), foram elaborados até o momento 54 mapas para verificar, primordialmente, o grau de manutenção de marcas de africanidade no português das comunidades afrobrasileiras analisadas ou, pelo contrário, de perda dessas marcas.

O critério fundamental da seleção dessas perguntas foi que no contínuo de respostas fosse possível contrapor variantes [+ afro] com variantes do que chamamos provisoriamente de português mais geral. Nesta etapa de análise, cabe primeiramente analisar de forma particularizada cada um dos mapas produzidos, a exemplo do que se fez em relação aos mapas do QFF.

\subsection{Resumo de macrotendências observadas}

A análise particularizada de cada um dos mapas elaborados para o presente artigo permitiu observar algumas macrotendências:

a) No plano diatópico, pode-se destacar as seguintes tendências:

1) MT01 (Complexo de Poconé) e MT03 (Complexo de Cáceres) são os pontos que mais conhecem a forma [+afro]. Por extensão, parecem ser os pontos com maior consciência das marcas de africanidade (v. mapas 023, 024, 025, 026, 028, 030, 032, 036, 038 que provam isso); 
2) MT04 (Complexo de Várzea Grande) e MT05 - Complexo de Chapada dos Guimarães sugerem um comportamento fortemente convergente e assimilável ao português do entorno. Têm, por isso, um comportamento regional próprio (cf. mapas 028b, 029a, 029b, 034a, 036a, 036b, 040a, 041a). MT02 - Complexo de Barra do Bugres parece ser o ponto mais conservador, mesmo que muitas vezes predomine uma variante que poderia ser não exclusiva da influência afro;

3) por fim, MT06 - Complexo de Vila Bela da Santíssima Trindade (região de fronteira) constituiu um ponto à parte, com um comportamento ainda indecifrável com perda acentuada da forma [+afro]; assimilação do português do entorno; contrastando com marcas de africanidade; como em parte também MT07 - Complexo de Santo Antônio do Leverger;

4) os pontos MT07 - Complexo de Santo Antônio do Leverger, MT04 (Complexo de Várzea Grande) e MT05 (Complexo de Chapada dos Guimarães) muitas vezes compartilham comportamentos que parecem sinalizar uma influência do centro urbano em torno (Baixada Cuiabana);

5) O ponto MT04 (Complexo de Várzea Grande) parece ser o ponto que mais reflete a influência do contato linguístico colonial, ao lado do ponto MT01 (Complexo de Poconé) que também possui influência colonial, pelo menos na variação fonética (cf. mapas 001-003, 015, 016).

6) O ponto situado mais ao norte MT02 (Complexo de Barra do Bugres) e, em posição intermediária, MT05 (Complexo de Chapada dos Guimarães), levantam a hipótese de influência paulista de um português popular de base caipira, provavelmente em virtude das rotas de bandeirantes, por exemplo, na ocorrência de $/ \mathrm{r} / \mathrm{retroflexo.}$ Compartilham igualmente marcas que parecem contrastar com o português mais geral do Brasil.

b) $\mathrm{Na}$ dimensão diassexual, evidencia-se, de modo geral, que as mulheres, mesmo as GII, tendem a um comportamento de maior adesão às inovações ou às variantes do português do entorno, de fora das comunidades afro-brasileiras. Isso pode se explicar pelo papel social das mulheres que mantinham um contato maior com falantes lusos, tendo em vista sua atividade como servindo os senhores/os donos.

c) Os falantes homens GII, em contrapartida, parecem constituir o grupo mais conservador. Entre os jovens, é também primordialmente o grupo GIm que mais mantém variantes [+afro] no português (v. mapa 022).

d) A análise da variação lexical do português das comunidades afro-brasileiras analisadas no RS sinaliza fortemente uma mudança em curso em dois sentidos:

1) de um lado constata-se, através dos dados cartografados (mapas 023 a 042 ), uma perda significativa de variantes [+ afro] da GII para GI. Uma série de mapas (v. mapa 022 - QFF e mapas 036a e 041a - QSL etc.) apontam para esta tendência;

2) de outro lado, verifica-se no sentido contrário uma reintegração de formas [+ afro], provavelmente resultantes em grande parte do português geral falado no entorno destas comunidades tanto de/quanto de uma consciência identitária acentuada por meio do movimento negro; a comparação diageracional permite levantar essa hipótese.

\subsection{Dimensão diatópica: condicionamentos sócio-geográficos}

Um fato em especial ficou óbvio na pesquisa desenvolvida nas sete comunidades afro-brasileiras selecionadas: cada ponto se distingue linguisticamente do outro, isto é, a variação diatópica é inegável e reflete muitas vezes a variação do próprio português mato-grossense. Cada comunidade teve, além disso, uma gênese, formação e desenvolvimento totalmente diversos. Definir as comunidades afro-brasileiras do Mato 
Grosso como uma territorialidade linguística homogênea não seria, por isso, adequado, pois a variação observada e a ser analisada se espalha para além das espacialidades a que estão restritos/confinados os falantes.

Ficou claro, neste estudo, mesmo que reduzido a poucos pontos, que essas ilhas linguísticas estão cada vez mais em contato dialetal com seu entorno. O que facilita isso hoje em dia são as aberturas de estradas que chegam até as comunidades mais isoladas, como é o caso de MT01, MT02, MT03, MT05, MT06 e MT07. Estes pontos viveram de duas décadas para cá uma experiência contatual intensa, onde só tinham vizinhos próximos, passaram a ter contato com os demais moradores de suas regiões e, principalmente, a presença do Estado.

Em termos linguísticos, a proximidade com "as cidades" fez com que o contato linguístico acrescentasse e substituísse vocábulos, influenciasse na norma gramatical; mas isso não impediu que essas comunidades mantivessem ao menos uma parcela de sua genuidade étnico-linguística obtida por herança ou transmissão diageracional. A fala dos afrodescendentes observada nas comunidades afro-brasileiras do MT representa uma variedade linguística de cunho popular que se insere no português mais geral falado no Estado e no Brasil. Não se constitui somente em uma variedade geograficamente delimitada, mas também numa variedade social; como preceitua Juliete Garmadi (1983)

Os resultados apontados pela análise dos mapas de variáveis do QFF e do QSL evidenciam a atuação de diferentes fatores sócio-históricos e geográficos na constituição da variedade do português de cada uma das comunidades. Entre esses fatores cabe salientar os seguintes:

$\left.1^{\circ}\right)$ localização geográfica próxima a um centro urbano;

$2^{\circ}$ ) localização geográfica próxima a uma área de contato histórico;

$3^{\circ}$ ) localização geográfica distante dos centros de irradiação;

$4^{\circ}$ ) localização geográfica nas proximidades de contato com demais grupos de fala minoritários (indígenas);

$5^{\circ}$ ) localização geográfico no âmbito de uma subárea de variação do português como língua supraregional;

$6^{\circ}$ ) origem da população que ocupa a comunidade;

Como se vê, a variação diatópica não surge da simples localização em determinado ponto do espaço, mas muito mais decorre da constelação de fatores sóciohistóricos que configuram e moldam esse espaço ao qual a língua e seus falantes pertencem.

\subsection{Dimensão diageracional: mudanças em tempo aparente}

Constatamos, na análise dos mapas linguísticos elaborados para este artigo, uma mudança em curso bastante generalizada, entre o português de falantes da GII, mais conservadores, e os jovens, da GI. Não é exagero admitir que essa é uma tendência observável na maioria dos contextos de uso de línguas minoritárias. O que não era esperado ao início da pesquisa foi a reincorporação ou reintegração de elementos de origem africana, como reflexo de processos de ressemantização em andamento no interior das comunidades através de movimentos sociais e políticas públicas. Essa tendência até certo ponto nova - presente sobretudo em pontos mais próximos justamente de centros urbanos - tem sua origem, ao meu ver, nas políticas recentes de inclusão e reconhecimento da cidadania pelos afrodescendentes. A política de cotas é um exemplo desse novo quadro social. Sua repercussão sobre a escolaridade e as relações de poder certamente também valem para o âmbito linguístico. Os jovens são neste sentido o grupo mais atingido por essas mudanças. 
Enquanto os falantes da GII por muito tempo mantiveram o contato linguístico apenas por convivência com o entorno, assim mesmo em uma postura de resistência e reclusão motivada pela discriminação e opressão social, a GI passou a abandonar uma posição meramente topostática e a entrar em contato com o entorno, originando casamentos interraciais (MT05); agricultura familiar (MT01, MT02 e MT03); rural/urbanização (MT04); presença do Estado (MT06); presença do Estado e proximidade com grande centro urbano (MT07).

Essas mudanças drásticas e muito aceleradas que afetaram inclusive a GII, que se manteve por vezes isolada no interior das comunidades de fala, fez com que a GI encarasse a modernidade social com mais interesse. Em termos linguísticos, essas mudanças sociais causaram e continuam a exercer uma força centrífuga nas comunidades que explica em grande parte as mudanças em tempo aparente observadas na análise dos mapas linguísticos.

Embora a presente pesquisa se centre na perspectiva sincrônica, o olhar diacrônico propiciado pela comparação diageracional, em tempo aparente, possibilitou uma série de respostas principalmente vinculadas à expressão de marcas de africanidade no léxico. No entanto, observamos que o uso de algumas variantes fonético-fonológicas ocorreram predominantemente entre os informantes da GII, enquanto outras são muito mais frequentes na GI. Da mesma maneira, verificamos variações com maior frequência no gênero feminino que no gênero masculino, como explicitaremos na seção seguinte.

\subsection{Dimensão diassexual: a fala de homens e mulheres}

Para a constituição do corpus e para posterior análise, durante a pesquisa de campo, tivemos a preocupação de manter um equilíbrio no número e perfil dos informantes para gravação da fala de homens e mulheres. Tínhamos sete pontos, portanto deveríamos ter no mínimo sete mulheres e sete homens de cada geração, totalizando no mínimo vinte e oito informantes. No entanto, esta meta pode ser atingida apenas parcialmente, visto que se obtiveram dezoito informantes mulheres e quinze informantes homens para este trabalho, sendo que em pontos como MT03 não se conseguiu, infelizmente, dados da GI, nem de homens, nem de mulheres. Para nossa grata surpresa mais pessoas se dispuseram a conceder entrevistas, muitas vezes juntos. Ou seja, em três entrevistas (MT01, MT02 e MT04) houve três informantes na GI. Nas entrevistas da GII, muitos preferiam participar como casal (MT01, MT02, MT04, MT05), nos demais pontos ou se entrevistou duplas, de irmãos ou mãe e filho, ou ainda em entrevistas individuais (exceto, como dissemos MT03). Em resumo, na maioria das entrevistas conseguiu-se, conforme previsto, a pluralidade simultânea de informantes homens e mulheres. A pluralidade simultânea de informantes permitiu medir o nível de conhecimento compartilhado, principalmente na GI, em que um informante se lembrava e o outro confirmava.

De maneira geral, os resultados expressos pela cartografia do QFF e do QSL apresentam um resultado equilibrado, com ligeiro caráter inovador por parte das mulheres, de maior aproximação às marcas linguísticas do português mais geral. A razão é simples, como pude observar durante as saídas para a pesquisa de campo; na maioria das comunidades, as entrevistas foram inicialmente marcadas com as mulheres; sendo a recepção feita por mulheres e os informantes que primeiro se prontificavam a conceder entrevista, as mulheres. De modo geral, portanto, as mulheres estão à frente das entrevistas realizadas nas comunidades afro-brasileiras deste estudo. Exceção se faz aos pontos MT01 e MT04 que possuem lideranças masculinas, porém com mulheres à frente. Esse fato permite observar que não há diferenças significativas entre homens e 
mulheres. No nível fonético-fonológico, as variações aparecem equilibradas entre homens e mulheres. No nível semântico-lexical, as variantes [+ afro] tendem a partir das mulheres acompanhadas pelos homens. Ou seja, as mulheres dos sete pontos pesquisados detêm marcas [+afro] tanto no nível do léxico quanto no fonéticofonológico, apesar de equilibrado neste último. O que se evidenciou nos mapas, no entanto, denota um comportamento linguístico mais aberto às inovações provenientes do português do entorno.

Em suma, historicamente os homens afrodescendentes podem até ter estabelecido os primeiros contatos com o português do entorno, porém com o equilíbrio visto nos dias de hoje, conclui-se que os homens estão mais isolados no interior das comunidades afro-brasileiras do MT e são as mulheres que entram mais em contato com o português do entorno, de características mais gerais. Ao mesmo tempo, são elas preservam com mais ênfase, segundo as observações feitas in loco nas comunidades, suas heranças linguísticas.

\section{2. À guisa de conclusão: português afro-brasileiro ou português dos afro- brasileiros?}

A pesquisa sobre o português falado nas comunidades afro-brasileiras do MT está sendo engajada. Enfrentamos a questão histórica sobre o negro no MT que carecem, e muito, de pesquisas históricas e antropológicas a serem realizadas no Estado, e mais ainda, carecem de estudos de cunho pragmático-linguístico-cartográfico. A questão do contato entre línguas na formação da realidade linguística mato-grossense foi o nosso mote, mais especificamente a observação da fala das comunidades afrobrasileiras.

Muitas dessas comunidades têm a sua origem em antigos quilombos ou se formaram em torno de antigas propriedades rurais de seus senhores após a abolição da escravatura. Desde essa época, o português falado pelos mais velhos vem sendo transmitido de geração em geração no interior das comunidades. Esse processo foi lento e duradouro, mas corre o risco de se perder no esquecimento das gerações mais novas. O que alguns pesquisadores costumam denominar de "transmissão linguística irregular" (GUY, 1981 e 1989; BAXTER, 1992 e 1995; LUCCHESI; BAXTER; RIBEIRO 2009) - teria dado origem a uma variedade linguística do português muito diferente do português falado pelos colonos portugueses. E, devido ao isolamento em que essas comunidades de descendentes de escravos viveram no interior do Brasil até pelo menos a primeira metade do século XX, essa variedade bastante alterada do português foi sendo passada de geração em geração sem maiores alterações, até sofrer a crescente influência do português mais geral, principalmente nas últimas décadas; influência essa que se reflete nos padrões de variação e mudança linguística que se observam hoje, como se viu neste estudo, nas comunidades afro-brasileiras do MT.

O processo de transmissão linguística irregular pode produzir mudanças significativas na estrutura da língua dos dominadores, que é assimilada, nesse tipo de contexto histórico, pelos povos dominados. Esse segundo caso se ajusta melhor à história sociolinguística das comunidades afro-brasileiras do MT. Ou seja, o contato entre o português e as línguas africanas no MT promoveu uma série de mudanças nas variedades da língua portuguesa falada no transcorrer da história linguística do MT, sobretudo, nas que se mantiveram em semi-isolamento na zona rural (MT02). O resultado mais notável de todo esse processo é o amplo e profundo quadro de variação no uso das regras fonético-fonológicas, algumas observadas neste artigo, que diferencia o português mais geral do português empregado nessas comunidades, onde, ao que tudo 
indica, a língua se mantém estável no que diz respeito a esse aspecto, com exceção onde os contatos linguísticos foram mais intensos e duradouros.

O fato empírico que fundamenta tal análise é o de que, em todas as situações em que ocorre o contato maciço entre línguas, se observa uma redução/eliminação do componente lexical do lado mais vulnerável, neste caso, os afrodescendentes. Portanto, seria muito improvável a ampla variação no uso do português contatual no MT. Através da macroanálise da variação do português falado nas comunidades afro-brasileiras foi possível identificar, na "dança social" das variantes que formam o repertório linguístico dessas comunidades, as mudanças no comportamento linguístico de seus membros, considerando a origem histórica e os contatos linguísticos a que se encontram submetidos nos respectivos territórios/ilhas linguísticas (cf. ALTENHOFEN, 2014).

Todavia, somente o estudo dessas comunidades de fala não é suficiente para se esgotar a questão no MT. Para demonstrar que o português falado em cada uma das comunidades afro-brasileiras pesquisadas para este trabalho se desdobra em variedades locais específicas dentro do cenário mais amplo do português mato-grossense, seria necessário proceder a um estudo contrastivo dessas variedades do português de afrobrasileiros com o que Lucchesi; Baxter; Ribeiro (2009) concebem como português afrobrasileiro e, não apenas isso, adicionalmente com outras variedades do português falado no MT, que incluem mais genericamente as variedades das fronteiras do Estado e das áreas bilíngues indígenas do MT (ALTENHOFEN, 2008). Se for constatado que o nível de variação é mais elevado nas comunidades afro-brasileiras do que em outras comunidades existentes, a hipótese da relevância do contato entre línguas fica reforçada, já que se espera que os efeitos do contato entre línguas sejam mais evidentes nas comunidades de fala afro-brasileira, em cuja formação o processo de transmissão linguística irregular teria sido mais intenso (JEROSLOW, 1975; GUY, 1981; BAXTER, 1992; VOGT; FRY, 1996; CARENO, 1997; SOUZA, 1999; SOUZA, 2000; SOUZA, 2015; PETTER, 2001; BONVINI, 2002; LUCCHESI; BAXTER; RIBEIRO, 2009). Daí a importância de se realizar estudos mais amplos nos Complexos Comunitários Afrobrasileiros encontradas no MT, cotejando essas comunidades de fala afro-brasileiras com outras comunidades marcadas etnicamente.

Como se vê, mesmo que se tenha buscado, ao longo da análise, privilegiar um enfoque sincrônico do português e afro-brasileiros em comunidades quilombolas, sempre "escorregamos" para o terreno da ampliação do conhecimento acerca da história linguística do português, com ênfase ao MT. Os padrões de fala que se observam em uma mesma região, contudo, podem revelar o ritmo da difusão de padrões de comportamento linguístico no MT e em regiões fronteiriças, em última análise.

As línguas africanas que chegaram ao MT deixaram marcas aparentemente "muito tênues" nas comunidades de fala afro-brasileiras, predominantemente de resquícios esparsos que tratamos como "marcas linguísticas de africanidade". Por meio do princípio da pluridimensionalidade, foi possível entender melhor a dinâmica da manutenção, perda e reincorporação/reposição dessas marcas de africanidade no português falado nessas ilhas linguísticas. Chegamos à conclusão de que os padrões linguísticos seguem o mesmo destino das línguas minoritárias de modo geral, qual seja de idas e vindas na perda do patrimônio linguístico herdado frente à influência da língua oficial da cultura majoritária. Daí a tentativa de abordagem do português dos afrobrasileiros nos mesmos moldes do estudo da variação e do contato do português falado por outras comunidades de fala minoritárias.

\section{REFERÊNCIAS}


ALTENHOFEN, C. V. Os contatos linguísticos e seu papel na arealização do português falado no sul do Brasil. In: ESPIGA, Jorge; ELIZAINCÍN, Adolfo. (Org.). Español y portugués: um (velho) novo mundo de fronteiras e contatos. Pelotas, 2008, v., p. 129164.

. Bases para uma política linguística das línguas minoritárias no Brasil.

In: NICOLAIDES, Christine et al. (orgs.). Política e políticas linguísticas. Campinas, SP: Pontes Editores, 2013, p. 93-116.

. O "território de uma língua": ocupação do espaço pluridimensional

por variedades em contato na Bacia do Prata. In: FERNÁNDEZ, Ana Lourdes da Rosa Nieves; MOZZILLO, Isabella; SCHNEIDER, Maria Nilse \& CORTAZZO, Uruguay (orgs.). Línguas em contato: onde estão as fronteiras? Pelotas: Editora UFPel, 2014. p. 69-103.

BAXTER, A. N. A contribuição das comunidades Afro-Brasileiras Isoladas para o Debate sobre a Crioulização Prévia: um exemplo do Estado da Bahia. Actas do colóquio sobre "Crioulos de Base Lexical Portuguesa. ed. by Ernesto d'Andrade e Alain Kihm, 7-35. Lisboa: Colibri, 1992.

. Transmissão geracional irregular na história do português brasileiro -

divergências nas vertentes afro-brasileiras. In: Revista Internacional de Língua

Portuguesa 14. [Número especial]. Lisboa, dez. 1995. p. 72-90.

BONVINI, E. Palavras de origem africana no português do Brasil: do empréstimo à integração. In: NUNES, J. H. História do saber lexical e constituição de um léxico brasileiro. São Paulo: Humanitas / FFLCH / USP: Pontes, 2002.

CARENO, M. F. do. Vale do Ribeira: a voz e a vez das comunidades negras. São Paulo: Arte \& Ciência/UNIP, 1997.

GARMADI, Juliette. Introdução à sociolinguística. Lisboa: Dom Quixote, 1983. GUY, G. R. Linguistic Variation in Brazilian Portuguese: Aspects of Phonology, Syntax and Language History. PhD dissertation, University of Pennsylvania. Ann Arbor: University Microfilms, 1981.

On the nature and origins of Popular Brazilian Portuguese. In:

Estudios sobre Español de América y Linguistica Afroamericana. Bogota: Instituto Caro y Cuervo, 1989.

JEROSLOW, H. M. Creole characteristics in Rural Brazilian Portuguese.

Comunicação apresentada a Conferência Internacional sobre Línguas Pidgins e Crioulas. Universidade do Havaí, 1975.

LUCCHESI, D; BAXTER, A; RIBEIRO, I. O português afro-brasileiro. Salvador: EDUFBA, 2009.

MELlO, H; Altenhofen, C. V.; RAso, Tommaso (orgs.). Os contatos linguísticos no Brasil. Belo Horizonte: Editora UFMG, 2011.

PETTER, M. M. T. Africanismos no português do Brasil. História das idéias

linguísticas: Construção do saber metalinguístico e constituição da língua nacional. Eni

P. Orlandi (org.). Campinas: Pontes; Cáceres: Unemat Editora, 2001.

SOUZA, A. C. S. de. A concordância de gênero entre o sujeito e o predicativo na

fala da comunidade quilombola da Caçandoca. Dissertação de Mestrado em

Semiótica e Linguística Geral. São Paulo: Faculdade de Filosofia, Letras e Ciências Humanas, Universidade de São Paulo, 2000.

A variação da concordância de gênero entre o sujeito e o

predicativo na linguagem do Cafundó. Estudos Linguísticos XLVI. Seminários do

GEL. Bauru: Universidade do Sagrado Coração, pp. 208-214, 1999. 
Africanidade e contemporaneidade do português de comunidades afro-brasileiras no Rio Grande do Sul. (Tese de Doutorado). Universidade Federal do Rio Grande do Sul. Porto Alegre, 2015.

THUN, H. La geolinguística como linguística variacional general (com ejemplos del Atlas linguístico Diatópico y Diastrático del Uruguay).In: International Congress of Romance Linguistics and Philology (21.: 1995: Palermo). Atti del XXI Congresso Internazionale di Linguistica e Filologia Romanza. Org. Giovanni Ruffino. Tubingen: Niemeyer, 1998. v. 5, p. 701-729, incluindo resumo dos tópicos principais da seção 5, p. 787-789.

Movilidad demográfica y dimensión topodinámica. Los

montevideanos en Rivera. In: RADTKE, Edgar; THUN, Harald [orgs.]. Neue Wege der romanischen Geolinguistik: Akten des Symposiums zur empirischen Dialektologie. Kiel : Westensee-Verl., 1996. p. 210-269.

VOGT, C.; FRY, P. Cafundó - A África no Brasil. 1. ed. Campinas: Editora da Unicamp, 1996.

APÊNDICE

Gráfico do Mapa_002_QFF_03_aRRoz

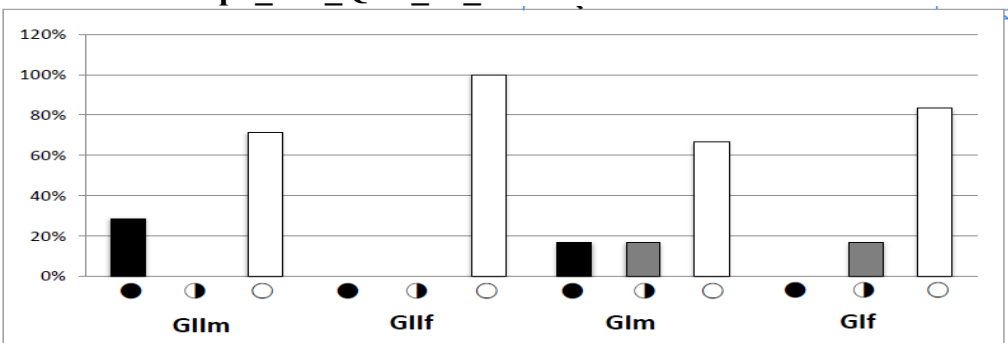

GIIm

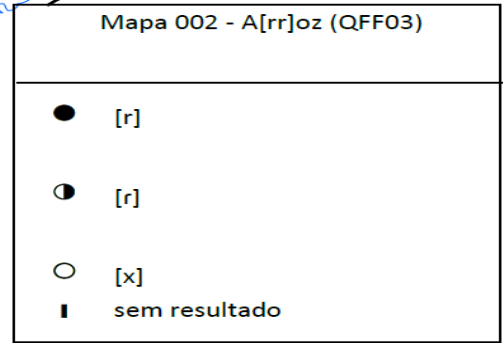

I sem resultado

Gráfico do Mapa_001_QFF_02_vaRRer
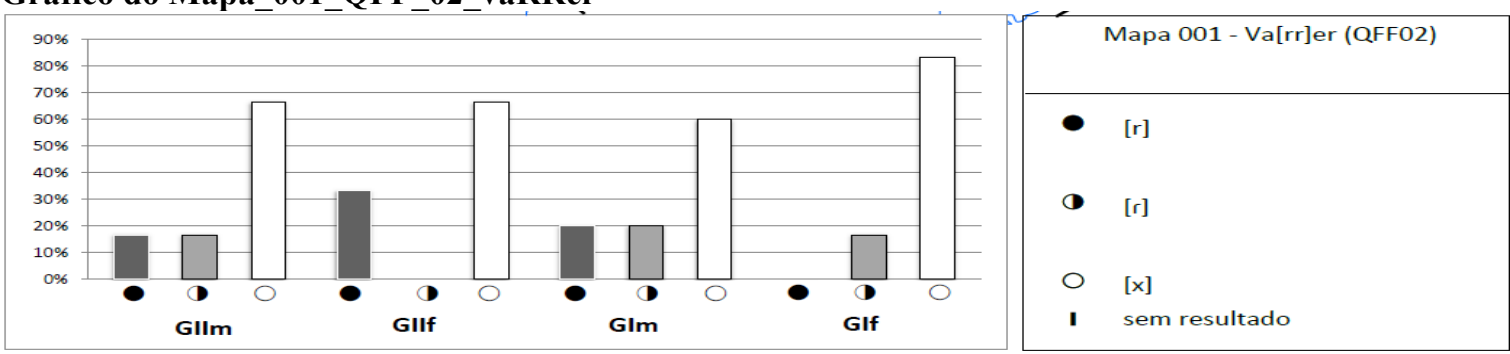

Gráfico do Mapa_003_QFF_19_caRRo
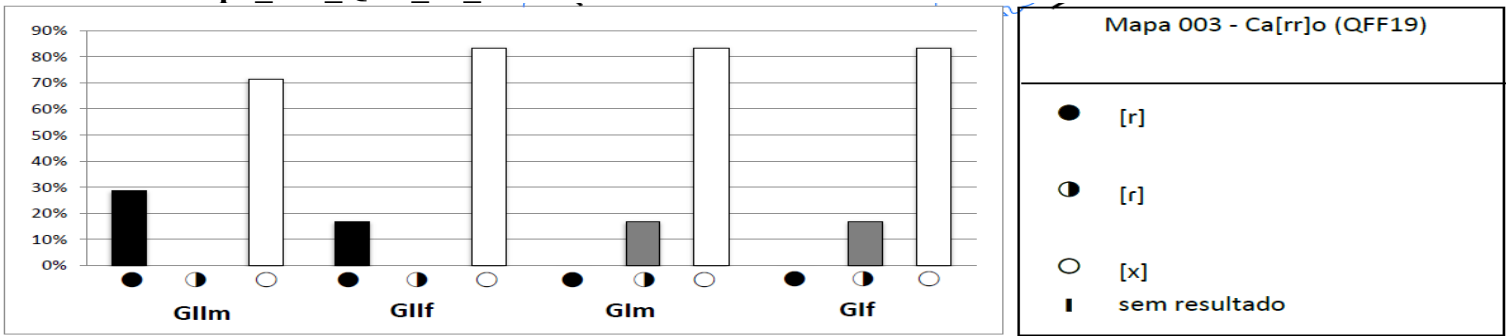
Gráfico do Mapa_015_QFF_08_noiTE

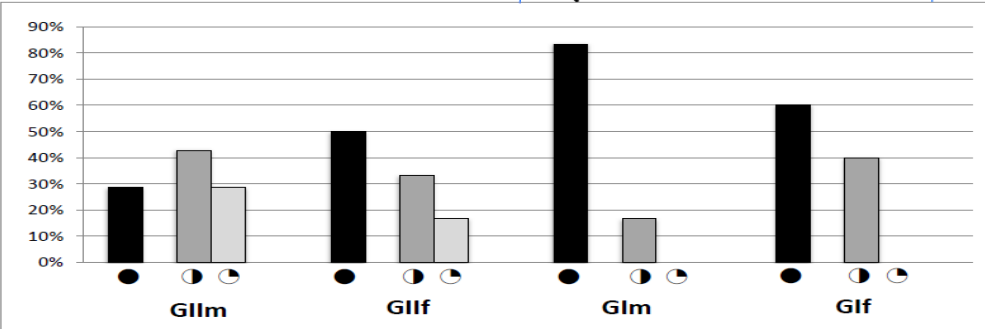

\begin{tabular}{|c|c|}
\hline & Mapa 015 - Noi[t]e (QFF08) \\
\hline & 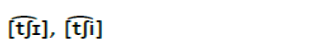 \\
\hline - & [tт] \\
\hline 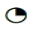 & [te] \\
\hline I & sem resultado \\
\hline
\end{tabular}

Gráfico do Mapa_016_QFF_09_tarDE

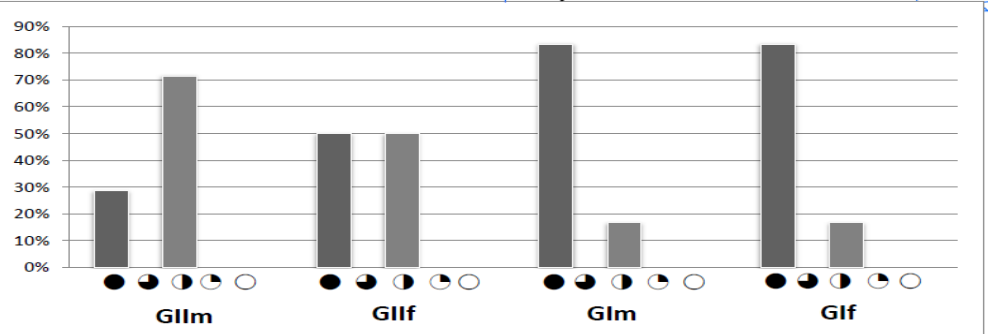

Mapa 016 - Tar[de] (QFFO9)

- $[\widehat{\mathrm{d} 3} \mathrm{I}]$

- [dr]

I sem resultado

Gráfico do Mapa_022_QFF_22_quase
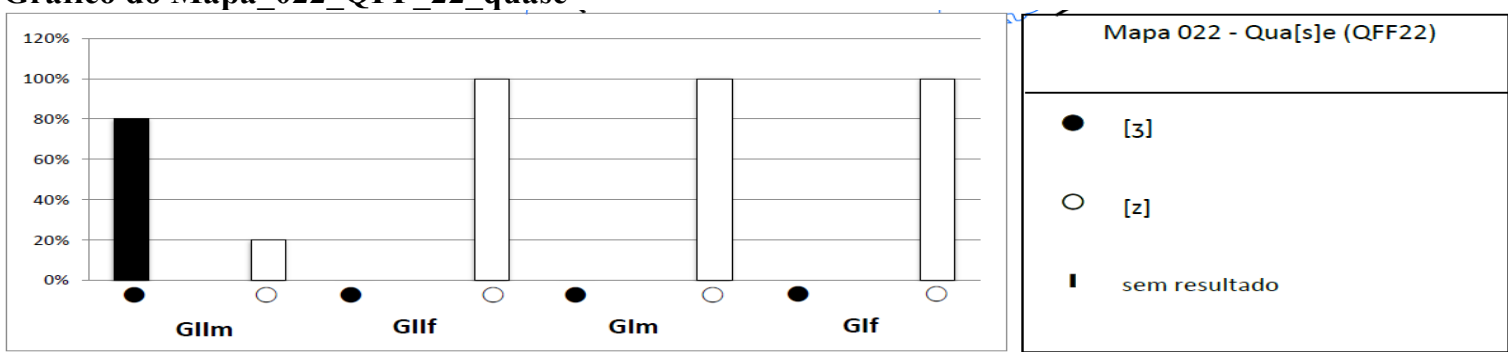

Gráfico do Mapa_023_sug banzé-auê-fuá_QSL_01_barulho

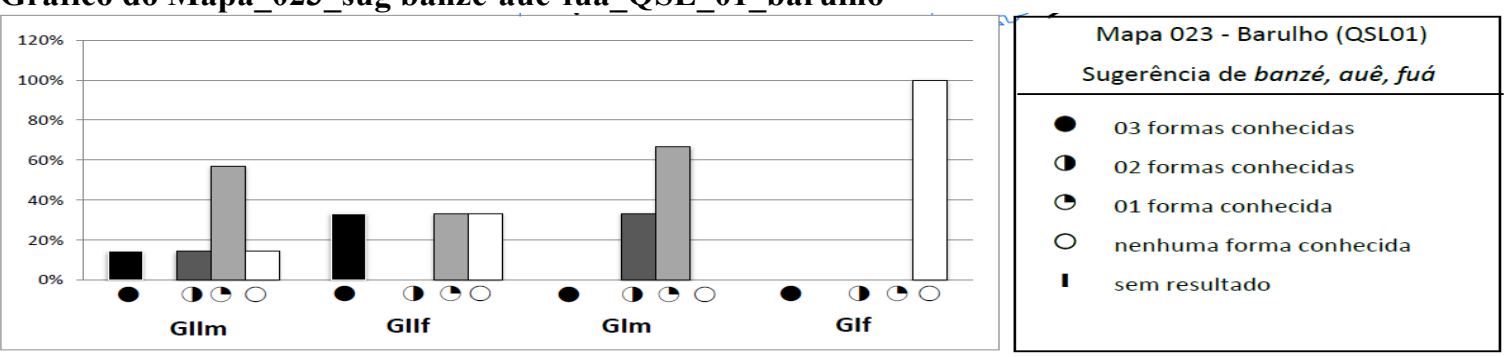

Gráfico do Mapa_025c_ocorrência moleque_QSL_04_menino 


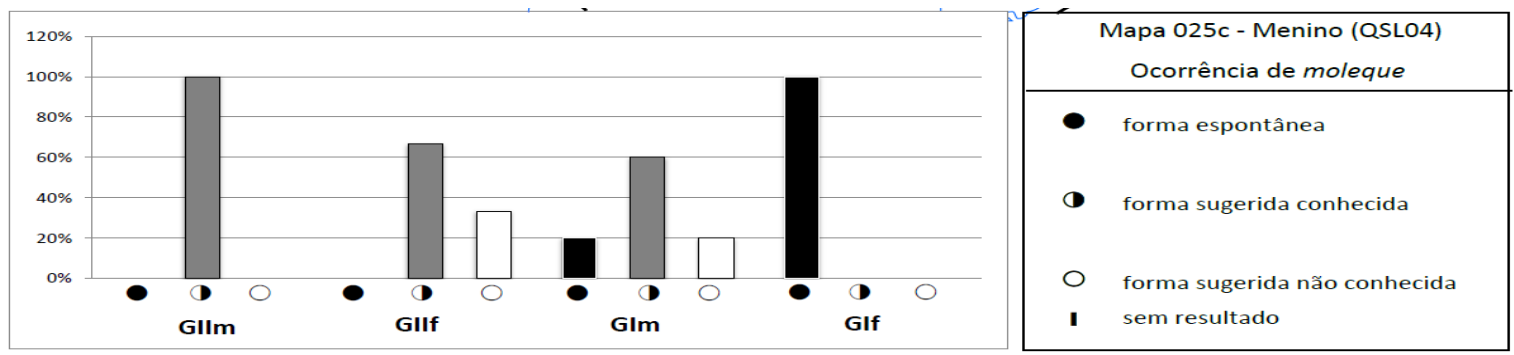

Gráfico do Mapa_026a_sugerência de fuzuê_QSL_10_desordem

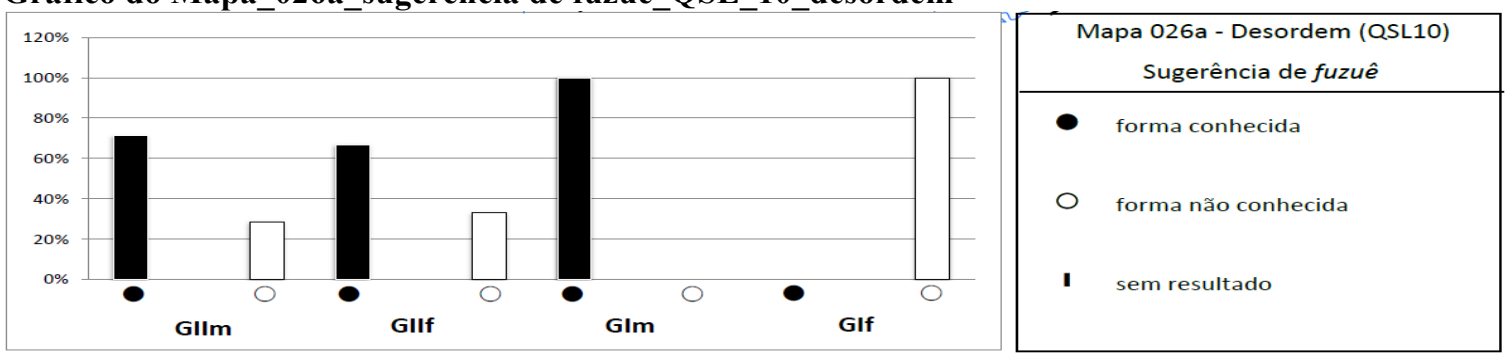

Gráfico do Mapa_026b_sugerência de furdunço_QSL_10_desordem

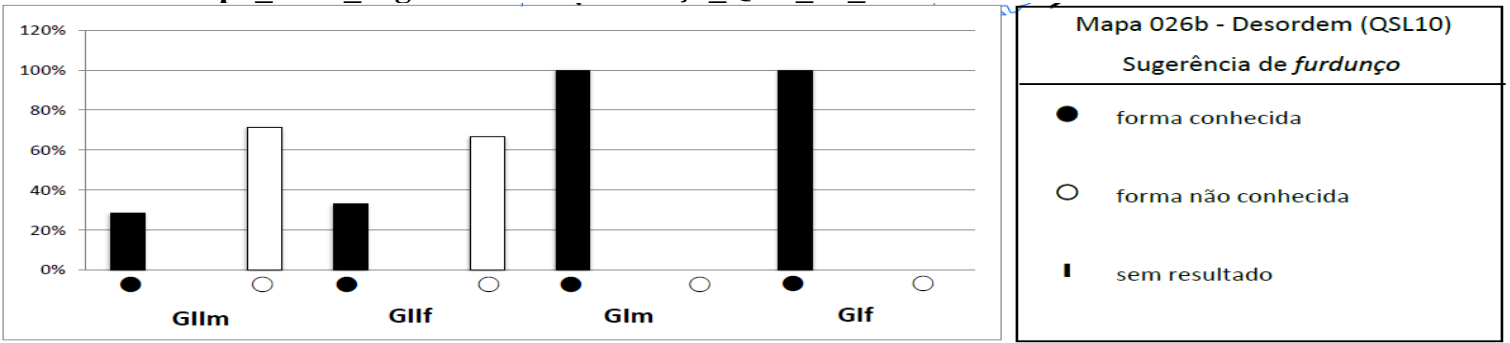

Gráfico do Mapa_026c_sugerência de fuzuêefurdunço_QSL_10_desordem

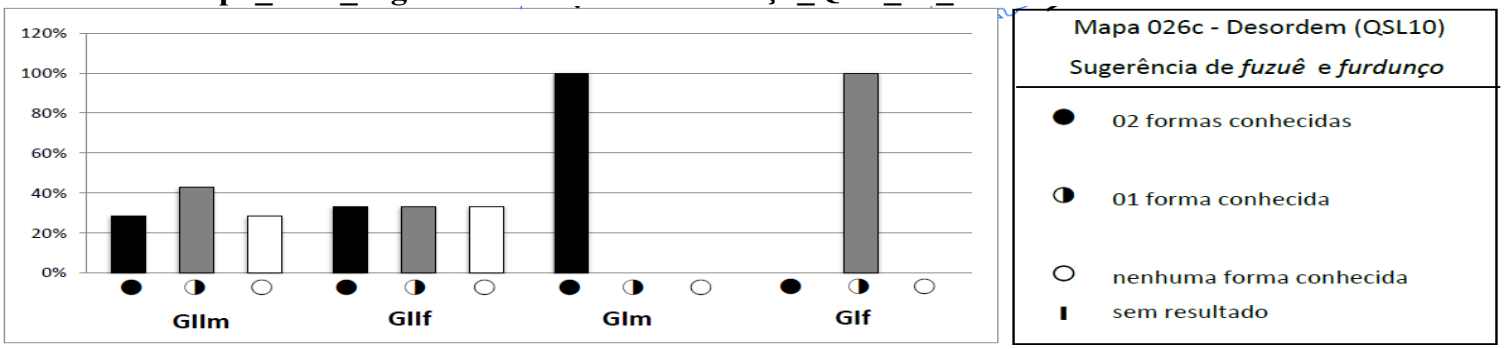

Gráfico do Mapa_028a_1a var_QSL_12_feitiço
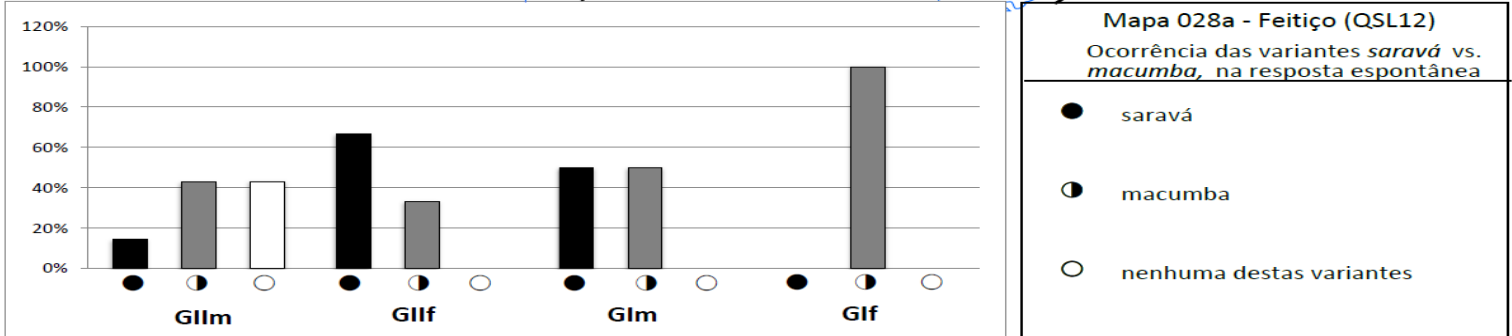

Gráfico do Mapa_028b_ocorrência mandinga_QSL_12_feitiço 

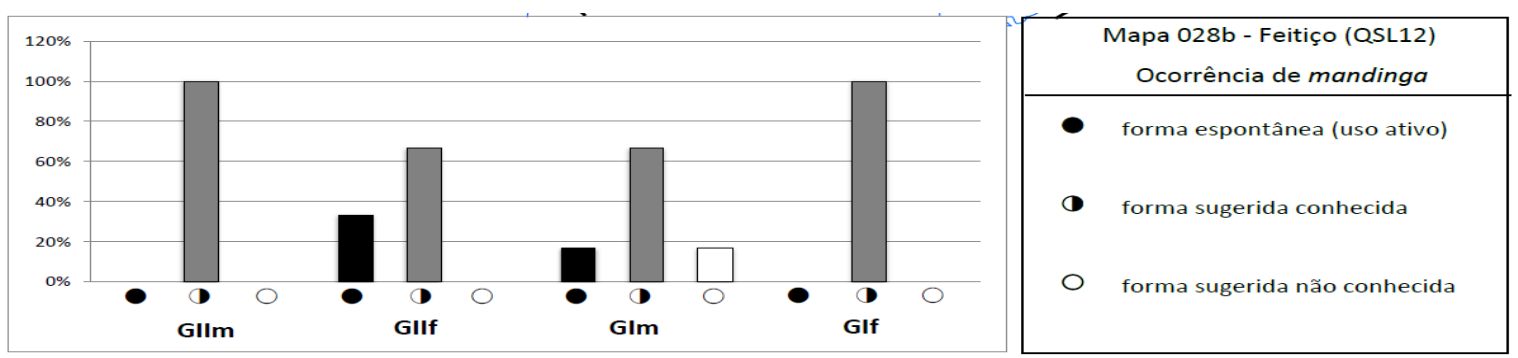

\section{Gráfico do Mapa_030_QSL_14_prostituta}
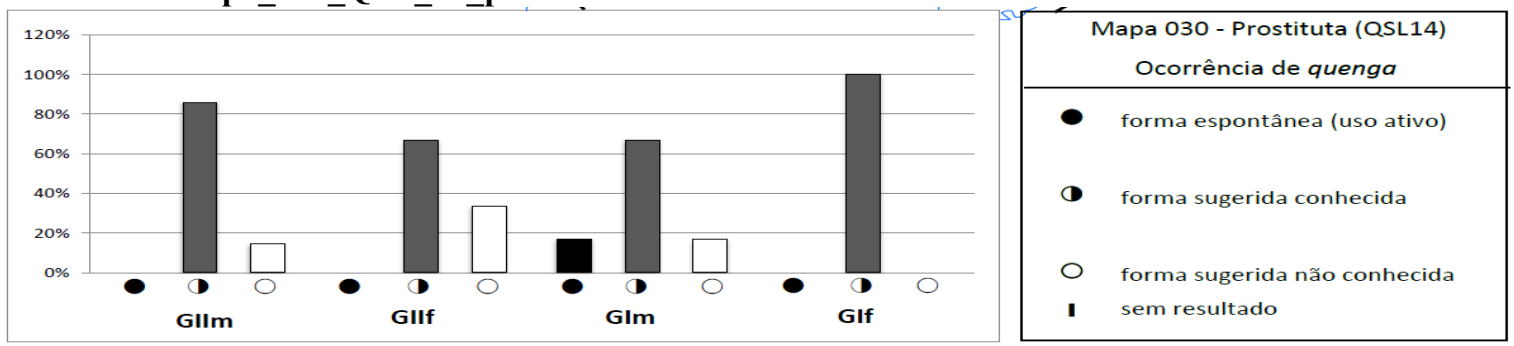

Gráfico do Mapa_032a_sugerência biboca_QSL_16_moradia

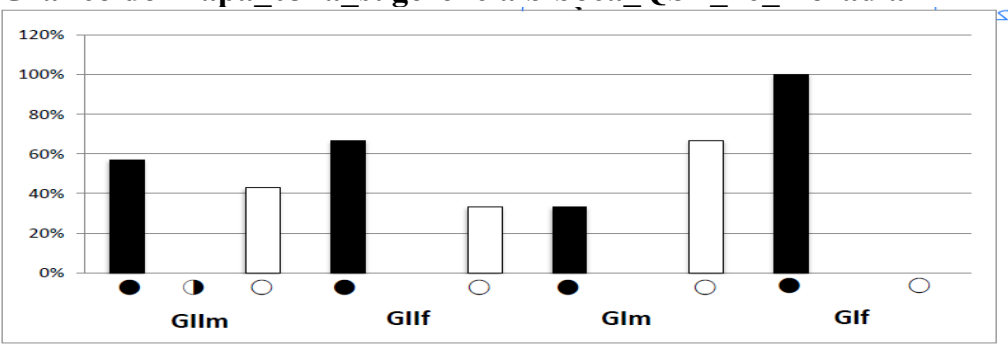

\begin{tabular}{|c|c|}
\hline \multicolumn{2}{|r|}{$\begin{array}{c}\text { Mapa 032a - Moradia (QSL16) } \\
\text { Sugerência de bibaca }\end{array}$} \\
\hline & forma conhecida \\
\hline 0 & forma não conhecida \\
\hline $\mathbf{I}$ & sem resultado \\
\hline
\end{tabular}

Gráfico do Mapa_032b_ocorrência cafofo_QSL_16_moradia

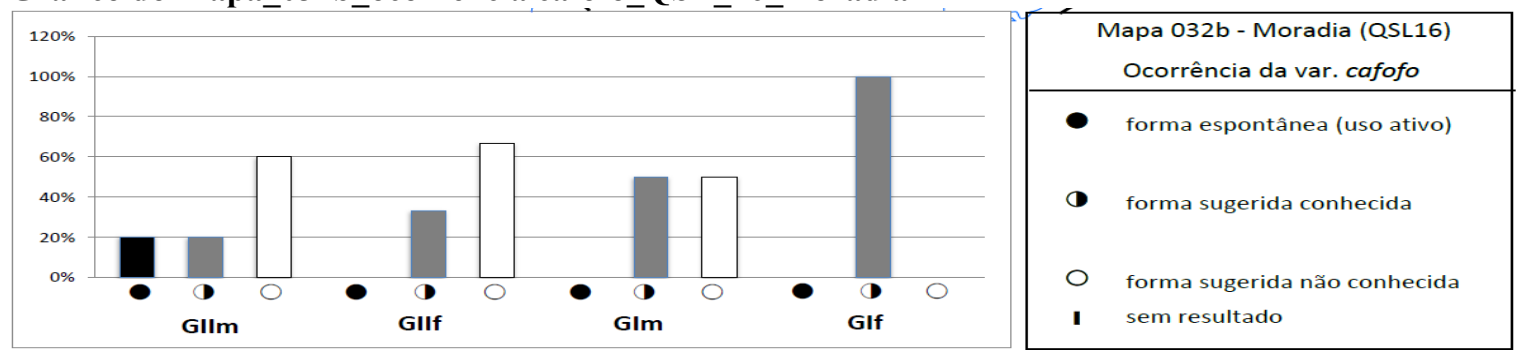

Gráfico do Mapa_032d_sugerência mocambo-mocó-cafofo-moquiço\#moquifo_QSL_16_moradia

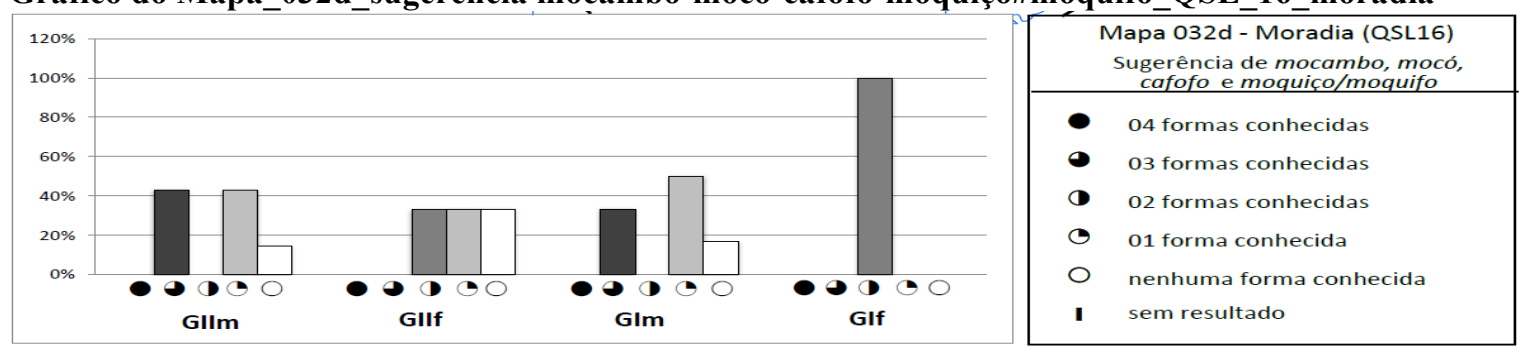


Gráfico do Mapa_038a_ocorrência bufunfa_QSL_25_dinheiro

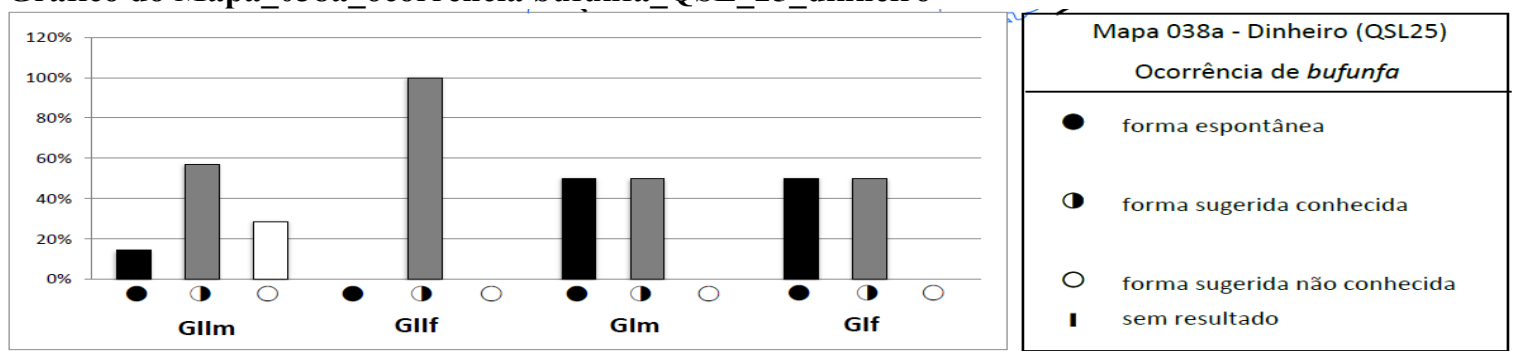

Gráfico do Mapa_038c_ocorrência dindim_QSL_25_dinheiro

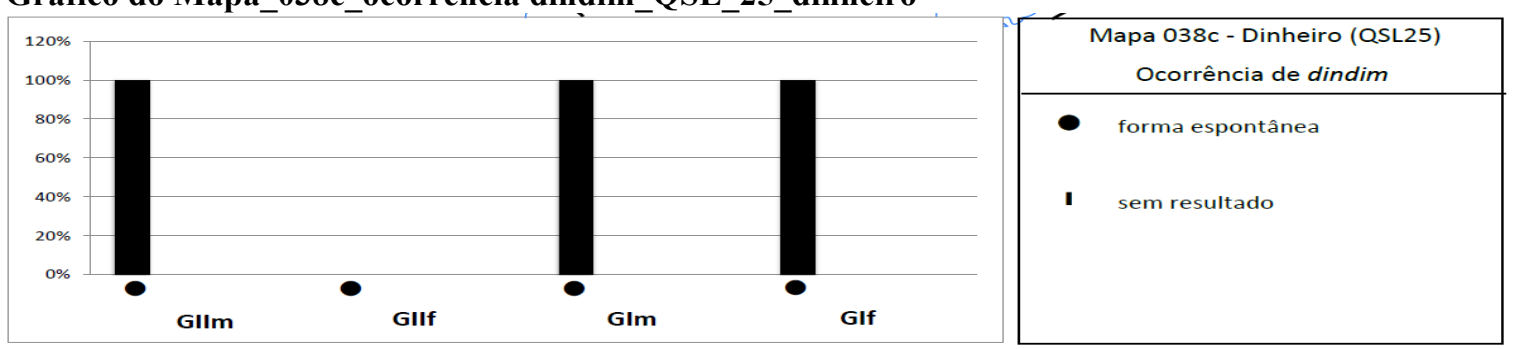

Gráfico do Mapa_041a_1a var_QSL_29_morrer
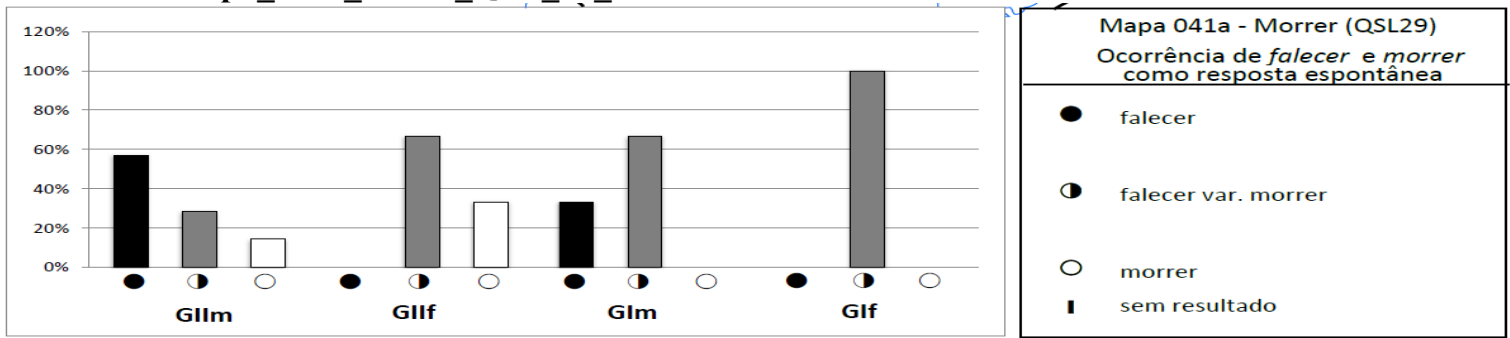

Recebido em: dezembro de 2018. Aprovado em: maio de 2019.

Como citar este trabalho:

SOUZA, A. C. S. de. Comunidades Quilombolas do MT: descrição do português falado. Traços de linguagem. V.3, n.1, p. 75-88, 2019. 